\title{
Articulação da Rede de Atenção Psicossocial e continuidade do cuidado em território: problematizando possíveis relaçóes
}

| ${ }^{1}$ Déborah Karollyne Ribeiro Ramos Lima, ${ }^{2}$ Jacileide Guimarães |

Resumo: O artigo discute os modos de articulação da Rede de Atenção Psicossocial (RAPS), considerando a recursividade que se estabelece entre estes e as características do cuidado continuado em território. Tratase de pesquisa de campo, com abordagem qualitativa, realizada com 22 sujeitos e tendo como cenário os serviços da RAPS Natal-RN. Foram realizados grupos focais e observação descritiva, sendo os resultados submetidos à análise de conteúdo temática e agrupados em duas categoriais: 1) A rede alinhavada: bordando ilhas de resistência entre as reminiscências do manicômio discutindo-se as características do cuidado em saúde mental de base comunitária desenvolvido no município; e 2) O religar de fios e de nós alinhavando a redediscutindo-se as estratégias adotadas para promoção de interconexões que favoreçam a continuidade do cuidado de saúde mental em território. Chama-se a atenção para a recursividade que se estabelece entre o cuidado em território e a articulação da RAPS. Um cuidado pautado na especialidade, na medicalização e na fragmentação é produto e produtor de uma rede que se articula pontualmente, em um alinhavo disparado por rótulos e intersubjetividades.

> Palavras-chave: saúde mental; serviços de saúde mental; cuidado em saúde.

\author{
${ }^{1}$ Universidade Federal do Rio \\ Grande do Norte. Natal-RN, \\ Brasil (deborah.ribeiro.ramos@ \\ gmail.com). \\ ORCID: 0000-0003-0616-0286 \\ 2 Universidade Federal do \\ Rio Grande do Norte, Escola \\ de Saúde. Natal-RN, Brasil \\ (jaciguim@yahoo.com.br). \\ ORCID: 0000-0003-4664-5886.
}

Recebido em: 25/02/2019 Revisado em: 17/05/2019 Aprovado em: 21/05/2019 


\section{Introdução}

A Reforma Psiquiátrica brasileira eclode num campo profícuo de luta pelos direitos de cidadania, de interrogação da relação entre Estado e sociedade, avança em todo o território nacional e nos diversos âmbitos que conformam suas múltiplas facetas.

No campo epistemológico, vimos o aflorar de críticas e questionamentos à instituição asilar, aos pressupostos fundantes da psiquiatria e às estratégias de normalização e controle do "doente mental". Na esfera jurídico-política, a promulgação da Lei $\mathrm{n}^{\circ} 10.216$, seguida de um arcabouço normativo de leis, portarias e decretos ministeriais, reorientou a assistência em saúde mental no Brasil, o que findou por legitimar uma série de serviços que devem funcionar de forma articulada e pautada na assistência em território. Transversalizando tais transformaçóes, apostou-se na clínica ampliada e na representação não estigmatizante dos transtornos mentais (COSTA et al., 2011).

A partir de 2011, com a regulamentação da Portaria no 3.088, surge um novo arranjo organizativo de serviços e estratégias, que propóe a integralidade e continuidade do cuidado, a integração e interação de serviços e a construção de vínculos horizontais entre atores e setores, em contraposição à fragmentação de programas e práticas clínicas, ações curativas isoladas em serviços e especialidades: a Rede de Atenção Psicossocial (RAPS) (BRASIL, 2011a).

Tal proposta organizacional para a saúde mental, oriunda do modelo de redes de atenção à saúde (RAS), compreende componentes de diversos níveis de densidade tecnológica: Atenção Primária à Saúde (APS), na qual estão alocadas as Unidades Básicas de Saúde (UBS), os Núcleos de Apoio à Saúde da Família (NASF), as Equipes de Consultórios na Rua e os Centros de Convivência e Cultura; Atenção Especializada, que conta com os Centros de Atenção Psicossocial (CAPS) em suas diversas modalidades - CAPS I, CAPS II, CAPS III, CAPS ad II, CAPS ad III e CAPS infanto-juvenil - definidos por ordem crescente de porte/complexidade e abrangência populacional; Atenção de Urgência e Emergência; Atenção Residencial de Caráter Transitório; Atenção Hospitalar, que é composta por leitos/enfermarias de saúde mental em hospital geral e pelo serviço hospitalar de referência; Estratégias de Desinstitucionalização como os Serviços Residenciais Terapêuticos (SRT) e o Programa de Volta para Casa; e Reabilitação Psicossocial através de empreendimentos solidários e cooperativas sociais (BRASIL, 2011a). 
Como êxitos da saúde mental/atenção psicossocial brasileira na última década elencam-se: o aumento da acessibilidade ao cuidado em saúde mental, a redução de leitos em hospitais psiquiátricos, a reorientação assistencial com foco na comunidade e nos espaços de sociabilidade dos sujeitos (PITTA, 2011), a criação e ampliação de dispositivos substitutivos e iniciativas de geração de emprego e renda articuladas às políticas de economia solidária (DELGADO, 2015), o aprofundamento do processo de expansão e regionalização da rede de serviços, apesar da persistência de "vazios assistenciais" em diversos pontos de atenção (MACEDO et al., 2017).

Apesar dos incontestáveis avanços, há que se problematizar as fragilidades, umas remanescentes e outras que afloram com a criação da RAPS. Deficiência estrutural de serviços comunitários, precarização dos vínculos profissionais, ausência de mecanismos de monitoramento e avaliação - da RAPS e da própria política pública de saúde mental -, disparidade entre a efetividade de serviços nos diversos contextos nacionais; critérios pouco claros de cobertura territorial efetiva, baixa densidade de articulação das ações intersetoriais, ausência de estratégias claras para enfrentar a vulnerabilidade social dos indivíduos (DELGADO, 2015), atenção à crise e centralização do CAPS como organizador do cuidado em território (LOBOSQUE, 2011) são alguns dos tensionamentos da rede evidenciados na literatura.

Considerando a importância da integração e articulação dos serviços em rede para a continuidade do cuidado em saúde mental de base territorial, engendramos pesquisa científica que buscou responder ao seguinte questionamento: como se dá a articulação entre os pontos da Rede de Atençáo Psicossocial (RAPS) do município de Natal com vistas à continuidade do cuidado em território? Assumimos o desafio de visitar os modos de articulação da RAPS na perspectiva de (re)conhecer remanescências da ideologia manicomial, assim como de outras fontes de tensão e travamento no cotidiano da assistência à saúde mental em rede.

A presente pesquisa se justifica pela representatividade da problemática da (des)articulação dos serviços como fator impactante no cotidiano da assistência à saúde mental coletiva. Além disso, intencionamos dar voz aos sujeitos implicados em diversas realidades e posiçóes dentro da rede, muitos dos quais historicamente experienciam a política de saúde mental apenas por intermédio das atividades desenvolvidas pelos técnicos no interior dos serviços especializados, estimulando a reflexão e o debate sobre o cotidiano da saúde mental e tendo como fio condutor os modos de articulação entre os serviços. 
O presente artigo objetiva discutir os modos de articulação da Rede de Atenção Psicossocial de Natal/RN, considerando a recursividade que se estabelece entre estes e as características do cuidado continuado em território. Isso porque reconhecemos que as formas de lidar com o transtorno mental influenciam e são influenciadas pela maneira como os serviços se organizam para atender às demandas dos usuários.

\section{Método}

O caminhar teórico deste estudo, resultante de tese de doutorado, buscou trilhar a interface entre a Saúde Mental e a Saúde Coletiva, tendo o Pensamento Complexo, de orientação moriniana, enquanto lente compreensiva do fenômeno em foco (MORIN, 2015; MORIN, 2013). Concordamos que utilizar-se das lentes da Complexidade significa assumir princípios teóricos importantes como intersubjetividade, incerteza, interioridade, recursividade, auto-organização, emergência (SANTOS, 2011). É, antes de tudo, apoiar-se em uma abordagem que se contrapóe ao reducionismo e ao determinismo positivista hegemônico, o que nos possibilita lançar um olhar ampliado diante da RAPS, que é essencialmente complexa.

Trata-se de pesquisa de campo, com abordagem qualitativa e enfoque exploratóriodescritivo que teve a Rede de Atenção Psicossocial como objeto de estudo. A abordagem qualitativa é indicada pela valorização dos aspectos subjetivos inerentes à atividade humana, criadora, efetiva e racional, apreendida através do cotidiano, da vivência, e da explicação do senso comum (MINAYO, 2014).

A pesquisa foi realizada na rede de serviços de saúde do município de Natal/RN, contemplando os cinco Distritos Sanitários (DS) da cidade. Estudamos serviços da atenção primária, secundária e terciária, que foram selecionados de maneira aleatória, buscando contemplar os diversos componentes da RAPS em conformidade com a capacidade instalada no município, assim como os cinco DS da cidade. De tal modo, compuseram o cenário da pesquisa cinco USF, quatro CAPS, dois no DS Leste, uma UPA, uma Unidade de Atenção Psicossocial localizada em hospital geral e um Serviço Residencial Terapêutico.

São 22 os sujeitos da pesquisa - diretores, trabalhadores e usuários dos serviços loci -, selecionados intencionalmente por conveniência, de maneira não probabilística e privilegiando sujeitos sociais que julgamos dispor de uma visão abrangente sobre a dinâmica dos serviços da RAPS. A composição da amostra foi 
delimitada pelo critério da saturação teórica, conforme orientaçôes da literatura (DESLAURIERS; KÉRESIT, 2010).

Foram incluídos diretores de unidades em desempenho de funçôes relacionadas à gestão/administração do serviço, trabalhadores em exercício de funções assistenciais em um ou mais serviços que compóem a RAPS/Natal e usuários ativos na rotina e nas atividades dos serviços de saúde mental, com condiçôes de comunicação durante o período de coleta dos dados e disponíveis para participar da sessão de grupo focal. Seriam excluídos da pesquisa os diretores e trabalhadores desligados de suas funçóes, aqueles que estavam de licença, férias ou atestado médico no período da coleta de dados, o que aconteceu em um único caso. Quanto aos usuários, seriam excluídos os que retirassem de maneira voluntária o seu consentimento para participação da pesquisa, fato que não ocorreu.

A coleta dos dados aconteceu no período de maio a outubro de 2017 e contou com a realização de sessōes de grupo focal e observação descritiva de serviços. Foram quatro sessóes de grupo focal, sendo uma com sete gestores, uma com seis trabalhadores e duas sessões com o mesmo grupo de usuários, contando a primeira sessão com nove participantes e a segunda com seis. A ausência de três sujeitos na segunda sessão do grupo com os usuários foi justificada por indisponibilidade de ordem pessoal em comparecer no dia e horário marcados. As sessóes de grupo focal tiveram duração média de 90 minutos e partiram de um roteiro que contou com duas questôes disparadoras.

A observação descritiva foi utilizada como instrumento complementar para aproximação à realidade empírica e focalizou pontos como acolhimento ao usuário, caminhos percorridos por usuários e técnicos dentro da RAPS Natal/RN e as açôes intersetoriais relacionadas ao suporte em atenção psicossocial. Cada serviço foi visitado no mínimo duas vezes, tendo cada visita entre uma e quatro horas de duração. As observaçôes encontradas foram registradas em um diário de campo (MINAYO, 2014).

A análise de conteúdo temática serviu de referencial para a análise do material proveniente da transcrição dos grupos focais e desdobrou-se em três etapas:

1) Pré-análise, com leitura flutuante do conjunto das comunicaçôes para constituição do corpus, elaboração dos recortes e categorização;

2) exploração do material com investigação dos dados brutos para reconhecimento do núcleo de compreensão do texto; 
3) tratamento dos resultados obtidos e interpretação, com inferências e interpretaçôes acerca dos achados (MINAYO, 2014).

Os resultados foram agrupados em duas categoriais analíticas:

1) A rede alinhavada: bordando ilhas de resistência entre as remanescências do manicômio;

2) O religar de fios e de nós alinhavando a rede.

Esta pesquisa foi encaminhada para apreciaçáo de um Comitê de Ética em Pesquisa, recebendo aprovação desta instância sob CAAE 65226817.5.0000.5292 e parecer 1.997.883. Respeitando o sigilo da identidade dos sujeitos, atribuímos aos participantes pseudônimos inspirados nos pontos de bordado em homenagem a esses atores, verdadeiros artesãos do SUS e da RAPS.

\section{A rede alinhavada: bordando ilhas de resistência entre as remanescências do manicômio}

O panorama apresentado representa mais um esboço de uma rede que se encontra em construção; alinhavada, pois em fase de expansão e criação de serviços.

Iniciaremos o debate trazendo à tona aspectos que se configuram, a nosso ver, como remanescências do manicômio materializadas em um simulacro de cuidado que envolve características como medicalização, fragmentação, especialização não comunicante e desacolhimento.

Nós trabalhamos a saúde mental no território, mas a gente ainda observa que o índice medicamentoso é muito alto, e isso faz com que o nosso usuário crie uma dependência (Areia).

Já estabilizou a doença, tomo remédio, quando eu tô sentindo que vou ficar um pouco mal eu procuro o CAPS e ela [a médica] ajusta o remédio (Estrela).

Pessoas que perdem um ente querido ou qualquer coisa que aconteceu, que naquele momento teve uma depressão e o médico passou um antidepressivo... Quando a gente vê o paciente já chega dizendo assim: “'eu tomo Clonazepam!”; “eu quero uma receita de Diazepam!" (Caseado).

Aí eu coloco na minha cabeça [que] é horrível [tomar medicação], mas é ruim com ele [o medicamento] e pior sem ele (Corrente). 
Percebe-se uma prática associada ao uso indiscriminado do medicamento, que tem como pano de fundo a medicação como recurso de escolha em detrimento do acolhimento e de outras estratégias de suporte psicossocial.

A medicalização é um fenômeno social, cultural e subjetivo de múltiplas determinaçôes. Termo que pode ser aplicado à prática de qualquer trabalhador da equipe interprofissional, basta que coloque no centro de sua açâo a resposta psicofármaca a priori; ou que só consiga ver os impasses sob o prisma do médico, fazendo encaminhamentos obrigatórios como sequência de sua prática (COSTAROSA, 2013).

Não desfazemos dos benefícios da medicação psicotrópica para o sujeito que apresenta transtornos mentais ou está em situação de abuso de álcool e outras drogas, mas problematizamos a redução da segunda situaçáo à primeira e colocamos em questão, assim como Guarido (2007), os efeitos de um discurso que naturaliza a existência e os sofrimentos e que revela a banalização do diagnóstico e o uso irrestrito de medicações como intervenção diante da vida.

A este respeito, e no que cumpre o uso pouco crítico do psicotrópico pelos usuários dos serviços de saúde, apontamos como alternativa a Gestáo Autônoma da Medicação (GAM) como estratégia e espaço aberto ao diálogo e à troca de experiências sobre o lugar que a medicação ocupa nas vidas dos usuários, esperandose, com isso, o empoderamento destes em relação ao uso do psicofármaco em seus projetos terapêuticos (ONOCKO-CAMPOS et al., 2013). Identificamos no caráter medicalizador do cuidado produzido em território uma das remanescências do manicômio na RAPS Natal-RN. Novo bordado com velhos fios?

Sea psiquiatria moderna inaugura a possibilidade decura da loucura aprisionando-a entre as paredes do asilo do século XIX, numa versão contemporânea, vemos o aflorar de uma nova fisionomia para o manicômio a partir da medicalização. CostaRosa (2013, p. 173) nos fala sobre os suprimentos medicamentosos e sua capacidade de redesenhar as funçóes do velho asilo, com as quais se repóe "pela via do consumo de medicamentos, todos os infelizes, os queixosos desajustados, os improdutivos para o trabalho e para o consumo".

A fragmentação da atenção e do próprio entendimento da linha de cuidado em atenção psicossocial aparece como uma das características do cuidado produzido em território. 


\begin{abstract}
Porque a saúde mental é justamente um paciente que ele tem um tratamento que vocês fazem [atenção especializada] e o que eu ofereço, que é a urgência e emergência (Aresta).

Porque a logística dos serviços ainda é direcionada em caixinhas, por exemplo a caixinha do HIV, a caixinha do hipertenso, a caixinha do diabético, a caixinha da saúde mental, e essas caixinhas hoje não se comunicam e é muito complicado (Coral).
\end{abstract}

Vemos a redução da saúde mental ao ato terapêutico, além da separação entre o que é de responsabilidade da atenção especializada e o que é atribuição da urgência e emergência. É fato que numa RAS cada componente desempenha funçóes peculiares, no entanto, é preciso que exista uma lógica organizacional que a atravesse, além de um sentimento de pertença e de responsabilização compartilhada entre os nós da rede.

A fragmentação de sistemas e práticas de saúde é preocupação antiga e foi expressada pela primeira vez no Relatório Dawson, em 1920. As discussões atuais sobre a temática apontam para a existência de um descompasso entre a situaçáo de saúde das populaçóes - caracterizada por uma tripla carga de doenças - e as respostas sociais engendradas para enfrentá-las - foco nas condições agudas ou agudização das condições crônicas (MENDES, 2011; OPAS, 2011).

Reconhecemos que uma lógica fragmentadora flutua entre os micro e macro contextos da saúde, atravessando a decomposição do corpo em partes, perpassando a organização fragmentada de políticas e sistemas de saúde e resvalando em práticas assistenciais segmentadas e com pouca comunicação com o contexto sociocultural de indivíduos e coletividades. Resquícios da razão cartesiana, na qual "separar para conhecer" é condição fundamental.

É marcante a presença da especialidade médico-psiquiátrica e do serviço especializado de suporte à saúde mental - o CAPS.

O psiquiatra do SUS, que eu faço [acompanhamento] lá no CAPS, não tenho o que dizer, super gente fina, faz o balanceamento dos remédios. Só é complicado porque é de dois em dois meses só (Corrente).

Mas quem disse que ele quer ir lá pra o médico de saúde da família?! Ele até vai, mas ele vai pedir um encaminhamento pra o especialista... Quando chega lá [no CAPS], se a gente faz o acolhimento e diz que ele não é pra lá, é confusão (Anjour).

Parece ainda estar viva a relação que se estabelece entre o indivíduo com transtorno mental/abuso de drogas e a figura do médico psiquiatra. Sem negar a importância do médico psiquiatra no contexto da atenção psicossocial, questionamos a relação 
de principalidade que a consulta psiquiátrica continua tendo frente ao repertório de estratégias de suporte psicossocial disponíveis na atualidade.

Rememorando a própria trajetória da loucura, como se vê em Foucault (2009), é sabido da captura da "doença mental" pelo saber da ciência psiquiátrica desde o século XIX, ainda que a partir do final do século XX tenhamos presenciado uma série de movimentos contestatórios e de ruptura com o saber da psiquiatria clássica. É inegável que séculos de hegemonia do saber médico-psiquiátrico e sua prática hospitalocêntrica, associada ao contexto de ascensão capitalista e neoliberal que fomentou (fomenta?) a indústria da loucura, deixaram marcas tanto nos modos de fazer da saúde mental - no que compete a processos de trabalho das equipes, organização dos serviços, (re)formulação de políticas públicas, imaginário popular de usuários, familiares - quanto da sociedade em geral.

Durante as sessóes de grupo focal, emergiram indícios de uma prática desacolhedora para com os usuários, seja na APS ou em outro ponto da RAPS. O "desacolhimento" ao qual nos referimos sinaliza a lacuna de práticas de produção e promoção de saúde que implicam responsabilização do trabalhador/equipe pelo usuário e escuta qualificada como condição fundamental para garantia de atenção integral, resolutiva e responsável (BRASIL, 2010).

Ele [o psiquiatra] apenas vai olhar pro outro prontuário e aí pergunta e baixa a vista. Aí vai e olha por aquele envelope passado, olha só assim e 'tome, tá aqui [a receita]!'(Nó Francês).

O que acontecia, eu digo assim acontecia sendo bem otimista, era [o usuário] chegar lá [na atenção básica], achar que a pessoa tem uma cara estranha e dizer: 'Não, esse com essa cara estranha é pra o CAPS’. Nem acolher, nem escutar... (Treliça).

As dificuldades para o acolhimento da pessoa em sofrimento mental na ESF são tema recorrente na literatura da área. Encontram-se justificativas como despreparo e falta de capacitação, insegurança do profissional no manejo com a pessoa em sofrimento psíquico e a incipiência de açôes de saúde mental na ESF (ANJOS et al., 2015) - aí já ponderamos que a própria dificuldade da equipe influencia também na incipiência de tais açôes no contexto da ESF.

Acrescentamos o preconceito fomentado por uma cultura manicomial ainda arraigada no imaginário de técnicos e da sociedade em geral, processos de trabalho que dificultam a realização de atividades que demandem tempo e sensibilidade, como é o caso do acolhimento. Some-se o fato de a ESF ainda trabalhar com foco 
em programas específicos, em consonância com políticas focalizadoras e que, por vezes, não se comunicam entre si.

Reconhecemos a importância do acolhimento para a reorientação do modelo técnico-assistencial em saúde e para fazer fluir o caminhar dos usuários pelas RAS. No campo da saúde mental coletiva, admitimos a exigência de tecnologias leves aquelas que, na compreensão de Merhy (2005), referem-se às relações de produção de vínculo, autonomização, acolhimento e gestão - aliadas à perspectiva emancipatória de operar o cuidado em conformidade com os pressupostos da Reforma Psiquiátrica. Visa-se, assim, a construção da autonomia, corresponsabilização e exercício da cidadania como condição fundamental para a integração de serviços e organização das redes (JORGE et al., 2011).

Contrastando com esse cenário, encontramos iniciativas pontuais que conferem fôlego aos movimentos de reforma psiquiátrica e à concretização da RAPS no cenário local. São experiências exitosas que, inspiradas em Bosco-Filho (2015), denominamos "ilhas de resistência".

A coordenaçấo de saúde mental vem promovendo muitas oficinas, fóruns, capacitaçóes exatamente porque é um processo difícil. (Treliça).

Antes a gente ficava muito fechado no nosso próprio território, dentro de quatro paredes. A gente não vai ressocializar ninguém entre quatro paredes (Abelha).

A gente vem desenvolvendo uma ação preventiva... Tenda do conto, Tapera da falaçáo... É mais uma escuta, é a partir dali que o usuário vai recordando lembranças, pessoas que perdeu (Areia).

As vivências grupais envolvendo profissionais e usuários são de fundamental importância, pois fortalecem os vínculos entre a comunidade e o serviço e entre os próprios usuários que se transformam em uma verdadeira rede de apoio social. Ademais, ao se trabalhar situaçôes que afligem os usuários e a comunidade, trabalhase a saúde mental de maneira transversal e na perspectiva da prevençáo, inclusive do suicídio. São atividades como estas que fortalecem a APS, qualificam o cuidado e possibilitam a construção das redes de saúde.

Vimos o despontar do CC como uma estratégia potente para inclusão social e desenvolvimento de práticas alternativas de cuidado. $\mathrm{Na}$ visão do profissional, este dispositivo aparece como um recurso terapêutico importante para a redução do tempo de permanência do usuário dentro do serviço. Na vivência do usuário, o CC exala liberdade e movimento, exercício de corpo, mente e cidadania. 
O Centro de Convivência [CC] foi muito positivo. Eles [os usuários] tinham algumas vocaçôes, alguns interesses que ainda estavam escondidos... A gente já viu a diminuição no número de dias dele dentro do serviço (Coral).

O que tiver pra eu fazer, eu faço, vou lá no CC, tem as oficinas de artesanato, tem a dança do ventre, tem meditação. Aonde tiver um canto pra eu ir, uma festa de aniversário, um passeio, se quiser passear só ou com um amigo... (Pétala).

O CC é uma unidade pública que faz parte da RAPS e que está alocada no componente APS. Constitui-se enquanto espaço aberto à população em geral, oferecendo um ambiente de sociabilidade, produção e intervenção na cultura e na cidade, convívio e sustentação das diferenças na comunidade e construção de laços sociais. São equipamentos estratégicos para a inclusão social das pessoas com transtornos mentais e em situação de abuso de álcool e outras drogas, sendo recomendados para os municípios com mais de 200.000 habitantes (BRASIL, 2011a).

No cenário estudado, o CC atende à demanda espontânea e a encaminhamentos. Apesar de a maioria dos frequentadores ser usuária encaminhada pelos CAPS da cidade, o CC de Natal/RN não é específico para usuários da saúde mental. A ideia é promover a integração entre as pessoas da comunidade na ocupação deste espaço, potencializando-o. Lá são desenvolvidas várias atividades que se propóem a trabalhar o corpo, a mente e a inserção social dos sujeitos, além de funcionar como ponto de encontro da comunidade. O CC se coloca como um disparador de fluxos dentro das redes e busca mesclar o institucional e o comunitário. Mantém contato mais estreito com os CAPS, com os Consultórios na Rua e com o movimento da População em Situação de Rua atuante na cidade.

Aceitamos que são as "ilhas de resistência” que dão o mote para a desconstrução das remanescências do manicômio, rumo às "boas práticas" em saúde mental, às quais se referem Thornicroft e Tansella (2010), à efetivação da RAPS em território e à concretização da Reforma Psqiquiátrica no Brasil.

\section{O religar de fios e de nós alinhavando a rede}

Ao longo da pesquisa, evidenciamos a coexistência de dois modos de articulação da RAPS Natal/RN: o primeiro como sendo o modo racional de produzir essas interconexões, ou seja, a implementação de sistemas instituídos/institucionalizados para fins de articulação da rede; o segundo é marcado por forças instituintes que atuam nos e para os processos de articulação da RAPS, são estratégias de escape 
à burocracia inerente ao compartilhamento do cuidado, facilitando, assim, a manutenção das interconexóes necessárias ao estabelecimento da rede. Percebemos que esta ainda é uma discussão que está sob o domínio técnico, o que é compreensível - porém inaceitável - se considerarmos o histórico da saúde mental brasileira que ainda hoje mantém a sociedade em geral à margem do processo.

Identificamos como estratégias formalizadas e instituídas para fins de interlocução entre os elementos que compóem a referida rede temática o uso do Sistema Nacional de Regulação (SISREG) e do apoio matricial em saúde mental.

A gente tem que marcar pela regulação. Ele [o usuário] chega pra gente, entrega a fichinha, a gente pega os dados dele e fica lá. Então, é uma dificuldade que a gente tem de marcar para a psiquiatria (Caseado).

O apoio matricial é o nosso carro-chefe pra fazer essa interação com os profissionais da rede (Abelha).

O SISREG é um sistema de informaçôes on-line disponibilizado pelo DATASUS para o gerenciamento e operação das centrais de regulação. É um software que funciona por meio de navegadores instalados em computadores conectados à internet, composto por três módulos independentes: a Central de Marcação de Consultas; a Central de Internação Hospitalar; e Autorização de Procedimentos de Alta Complexidade/Custo (APAC) (BRASIL, 2011b).

Em tese, o processo regulatório atua sobre o acesso dos cidadãos e a oferta de serviços, subsidiando o controle sobre os prestadores de serviços, seja para ampliar ou remanejar a oferta programada. A regulação do acesso deve exercer também a função de orientar a programação da assistência, assim como o planejamento e a implementação das açôes necessárias para melhorar o acesso dos usuários aos serviços de saúde especializados, isto porque se estabelece com base em protocolos clínicos, linhas de cuidado e fluxos assistenciais definidos previamente (BRASIL, 2011b). Entretanto, o que se vê no cenário estudado é o acesso dos usuários aos serviços especializados sendo regulado pela disponibilidade de oferta, ou pela falta dela. Como não há oferta suficiente para a demanda, simplesmente os usuários ficam sem atendimento, gerando, na APS, filas de espera para encaminhamentos. Para equilibrar esta tensão acarretada na rede, profissionais - diretores e trabalhadores - acabam se utilizando dos vínculos interpessoais, tendo o médico à frente da negociaçáo, enquanto que os usuários findam por recorrer à porta aberta do CAPS na perspectiva de terem sua demanda contemplada. 
A impressão que se tem é que a atividade de regulação - exercida via SISREG - vem atuando como uma espécie de "cancela" do sistema de saúde: abre passagem quando há disponibilidade de oferta e fecha o acesso ao sistema quando já não há mais vagas nas agendas dos profissionais especialistas. Com esta observação, pretendemos alertar para a regulaçáo enquanto estratégia de planejamento, programação, avaliação e reorganização dos sistemas de saúde e para o SISREG enquanto dispositivo de articulação da rede.

Em relação ao matriciamento em saúde mental, há que se problematizá-lo enquanto instrumento potente para articulação da rede.

Ano passado [2016] foi meio que uns rumores que o tratamento deles [usuários da saúde mental] seria feito dentro da unidade [UBS] também. Como é que vocês chamam quando a unidade [UBS] faz parte desse tratamento terapêutico? (Folha).

Fragmento do diálogo que aconteceu em uma das sessóes de grupo focal:

- Você sabe o que é matriciamento? Parece palavra lá do alto planejamento (Renascença).

- Você vai continuar seu tratamento sem precisar de tá com o psiquiatra todo tempo, aí você vai pra o clínico-geral que vai fazer sua receita dos medicamentos pra você ir pegar ou então comprar porque tá cheio demais o CAPS, tá muito cheio (Rococó).

- Aí pega e empurra pra clínico-geral tratar (Corrente).

No período de circulação pelos serviços, ficou evidente a fragilidade, especialmente na APS, em relação ao saber e ao fazer que envolvem o apoio matricial, apesar de reconhecerem a necessidade de tal prática para o cuidado em saúde mental de base comunitária. Por outro lado, é notória a dificuldade que os usuários têm de entender o que é o matriciamento e de reconhecer a importância dessa prática para a continuidade do cuidado, evitando reinternaçôes e potencializando outros espaços do cuidado para além dos serviços especializados em saúde mental.

O matriciamento ou apoio matricial constitui-se em um novo modo de produzir saúde no qual duas ou mais equipes trabalham na construçấo coletiva de projetos terapêuticos junto à população. Combina elementos de atenção clínica com características pedagógicas a fim de estimular o raciocínio, o diálogo e o compartilhamento de saberes, evitando a prescrição de condutas por parte da equipe especializada e proporcionando um espaço de estímulo ao crescimento das competências da ESF relacionadas à saúde mental (CHIAVERINI, 2011).

Interessa-nos pensar sobre o matriciamento em saúde mental sob dois ângulos distintos entre si, porém interligáveis e inter-relacionáveis. Sob a perspectiva de 
serviços e de técnicos, implica educação permanente, compartilhamento de saberes e de responsabilidades, construção coletiva de projetos terapêuticos. Para o usuário, resulta em compartilhamento do cuidado, livre circulação pelos serviços da rede com potencialização de outros espaços de cuidado, além de educação popular em saúde para subsidiar a compreensão da lógica organizacional do cuidado em rede.

São várias as barreiras enfrentadas por atores e serviços para a implementação do apoio matricial em saúde mental, em que pese sua potencialidade enquanto articulador das RAS. Desvinculação das práticas de saúde mental das atitudes voltadas para a doença mental - diagnóstico, consultas especializadas e medicação -, desmistificação da loucura no imaginário social com potencialização do acesso aos serviços de saúde e a adesão ao tratamento (CHIAVERINI, 2011), prática incipiente do diálogo interdisciplinar e do compartilhamento de consultas e de visitas domiciliares por equipes multiprofissionais na atenção básica (BRITO, 2014), agendamento e acompanhamento de casos de saúde mental pelos serviços da APS (DIMENSTEIN et al., 2018) são algumas das dificuldades relatadas por pesquisadores da área.

Inquietam-nos os prejuízos que compreensão e prática distorcidas do apoio matricial podem trazer ao processo de articulação da RAPS e que têm a ver com a (re)criação de rotas assistenciais que se estabelecem mais pela falta de conhecimento sobre a lógica organizacional da atenção em rede - que menospreza a prática do cuidado compartilhado e promove fluxos truncados em que circulam os serviços especializados - do que pela atitude empoderada de indivíduos que desenham eles próprios os caminhos que os conduzem ao cuidado integral.

Outro modo de articulaçáo evidenciado no contexto da RAPS Natal/RN diz respeito às estratégias de cunho intersubjetivo adotadas para a tessitura da rede e consequente continuidade do cuidado em território. Pelo que foi possível inferir, são essas estratégias as predominantes no cotidiano da referida rede.

Estratégias como contato telefônico, troca de mensagens via aplicativo de internet para smartphones, fóruns, reuniōes e debates emergiram como alternativas desenvolvidas pelos atores para transpor as barreiras burocráticas impostas pela própria instituição, a indefinição de fluxos assistenciais e as dificuldades provenientes de uma estrutura operacional tornada precária.

Lá no CAPS nós fazemos através de contato telefônico [ligação e via WhatsApp] e por escrito, faz os dois caminhos. A gente se articula bastante através dos vínculos pessoais que a gente tem, mas que não deveria ser, a gente utiliza porque é um instrumento importante (Brocatelo). 


\begin{abstract}
Reuniôes de compartilhamento de cuidado onde a gente discute caso a caso, a gente chama pra compartilhar com os outros serviços da RAPS -UBS, CAPS, SAD [Serviço de Atenção Domiciliar] - pra tá discutindo caso, fazendo o PTS do paciente, programando alta (Cordonê).
\end{abstract}

As falas dos sujeitos da pesquisa alertam para a representatividade dos vínculos interpessoais para os movimentos de articulação da RAPS Natal/RN.

Respeitando a subjetividade como um dos fios implicados na e para a tessitura das RAS por um lado, e reconhecendo que a articulação da RAPS se faz também pelo encontro entre os seus atores - gestores, trabalhadores e usuários -, dirigimos nosso olhar para o microespaço, o espaço "interseçor" (MERHY, 2007) que circunscreve esse encontro de e para produção da RAS, dentre elas a RAPS. Ali, naquele espaço "interseçor" que se forma no encontro entre profissionais de diferentes serviços - já que falamos em articulação de redes de saúde - e usuários, reconhecemos a coexistência de duas dimensóes: a que compete aos trabalhadores e suas intencionalidades e finalidades e aquela que compreende o usuário e suas demandas de saúde e de cuidado. Nesse momento de encontro e de negociação, um jogo de produção de redes e de compartilhamento do cuidado póe em confronto, nem sempre conflituoso, os sujeitos enredados nessa trama.

Estaria no espaço "interseçor" da produção das redes a justificativa para a força da intersubjetividade dos atores em face da articulação da RAPS Natal/RN? Imaginamos que por trás dessa tendência de se buscar inter-relaçôes com aquelas pessoas com as quais se tem mais afinidade, com as quais se compartilham opinióes, experiências e modos de conceber o cuidado psicossocial, estaria camuflado o desejo de produzir confrontos "harmoniosos" e minimizar desgastes. Cogitamos ainda que, em prol da tranquilidade de uma inter-relação que se estabelece entre pares, se permita perpetuar a autoridade e o poder do discurso médico como regulador/ articulador da rede reduzindo conflitos e tensôes.

Ponderamos que supervalorizar vínculos e afinidades interpessoais como estratégia para promover articulação da RAPS pode ser uma tentativa de camuflar o desejo de fuga de embates e tensôes por vezes necessários para fazer fluir a rede. É preciso enaltecer a potência do encontro como espaço para criação de vínculos entre trabalhadores e gestores, e não o caminho inverso, em virtude do qual se colocam as afinidades interpessoais como agenciadoras dos encontros em saúde. 


\section{Considerações finais}

Buscamos com esta pesquisa desvendar as características do cuidado produzido em território e evidenciamos em meio às práticas desenvolvidas características como medicalização, fragmentação do sujeito e das práticas, especialização não comunicante e desacolhimento. Por outro lado, reconhecemos que a articulação da rede em análise é pontual e prioriza os serviços especializados em psiquiatria/ saúde mental, com primazia das estratégias informais para a tessitura da rede, em detrimento de estratégias formais de articulação como o SISREG e o matriciamento em saúde mental.

Chamamos a atenção para a relação de recursividade que julgamos se estabelecer entre o cuidado em território e a articulação da RAPS. De modo que, um cuidado pautado na especialidade, na medicalização e na fragmentação é produto e produtor de uma rede que se articula pontualmente, num alinhavo disparado por rótulos e intersubjetividades. No âmbito da atenção à saúde em rede, há avanços discretos desenhando o cenário local que se materializam em iniciativas reconhecidas por nós enquanto "ilhas de resistência" e que vêm sendo bordadas entre as remanescências do manicômio.

A pouca adesão dos representantes da APS à realização de grupos focais separados pela posição que o sujeito ocupa na RAPS foi uma limitação desta pesquisa. Talvez, a junção dos diversos atores em um único grupo tivesse feito aparecer as relaçôes e os conflitos de poder entre estes. Ademais, a fluidez das "verdades" científicas, o volume de referências bibliográficas e o hiato entre a formulação de políticas públicas e a concretização destas no território nos fazem identificar no produto ora apresentado apenas um retrato da realidade local.

Reconhecemos a RAPS enquanto uma "rede viva", pois formada por serviços e pessoas em relações dinâmicas e dialógicas que se articulam recursivamente em um processo complexo, individual e coletivo e que envolve setores e, principalmente, atores e seus saberes, símbolos, afetos, memórias. É provavelmente por este motivo que mudar o arranjo organizacional em conformidade com as especificaçóes ministeriais, por si só, não garante a mudança de paradigmas, de processos de trabalho, de relaçôes interpessoais ou de percepçôes sobre a circulação de usuários pelos serviços e pelos espaços da cidade. Ao mesmo tempo, ponderamos que as transformaçóes no arranjo organizacional dos serviços brasileiros de saúde mental são um indicativo de que 
deslizamentos teórico-conceituais estão presentes na atualidade, tensionando as redes de produção de saúde e fazendo avançar a Reforma Psiquiátrica.

Reforçamos o valor de se reconhecer pujança no inacabado, de se discernir a potência da plasticidade no alinhavo de uma rede que se encontra em construção. Agora é o momento de apostar na complementaridade entre as diferenças de atores, serviços e setores, para, a partir das "ilhas de resistência" reconhecidas no território, religarmos saberes e práticas em prol da RAPS e da Reforma Psiquiátrica brasileira. ${ }^{1}$

\section{Referências}

ANJOS, M. A. et al. Acolhimento da pessoa em sofrimento mental na Atenção Básica para além do encaminhamento. Cadernos Brasileiros de Saúde Mental, v. 7, n. 15, p. 27-40, 2015.

BOSCO-FILHO, J. As liçôes do vivo: ciências da vida e complexidade. 2 ed. Natal: EDUFRN, 2015.

BRASIL. Ministério da Saúde. Conselho Nacional dos Secretários de Saúde. Regulação em saúde. Brasília: CONASS, 2011b.

. Ministério da Saúde. Gabinete do ministro. Portaria n. 3.088, de 23 de dezembro de 2011. Institui a Rede de Atenção Psicossocial para pessoas com sofrimento ou transtorno mental e com necessidades decorrentes do uso de crack, álcool e outras drogas, no âmbito do Sistema Único de Saúde (SUS). Diário Oficial da União, Brasília, DF, 30 jun. 2011a, Seçâo 1, p. 59.

. Secretaria de Atenção à Saúde. Núcleo Técnico da Política Nacional de Humanização. Acolhimento nas práticas de produção da saúde. 2 ed. Brasília: Ministério da Saúde, 2010.

BRITO, A. A. C. Matriciamento em saúde mental: atuaçấo de Núcleos de Apoio à Saúde da Família. Dissertação (Mestrado) - Departamento de Odontologia, Universidade Federal do Rio Grande do Norte, Natal, 2014.

CHIAVERINI, D. H. Guia prático de matriciamento em saúde. Brasília: Ministério da Saúde, 2011. COSTA, N. R. et al. Atores, política pública e instituiçôes da Reforma Psiquiátrica brasileira. Ciência e Saúde Coletiva, v. 16, n. 12, p. 4576, 2011.

COSTA-ROSA, A. Atenção Psicossocial além da Reforma Psiquiátrica: contribuiçōes de uma clínica crítica dos processos de subjetivação na Saúde Coletiva. São Paulo: Editora UNESP, 2013. DELGADO, P. G. Limites para a inovação e pesquisa na reforma psiquiátrica. Physis, v. 25, n. 1, p. 13-18, 2015.

DESLAURIERS, J. P.; KÉRISIT, M. O delineamento da pesquisa qualitativa. In: POUPART, J. et al. (Orgs.). A pesquisa qualitativa: enfoques epistemológicos e metodológicos. 2 ed. Petrópolis: Vozes, 2010. p. 20-39. 
DIMENSTEIN, M. et al. A saúde mental e atenção psicossocial: regionalização e gestão do cuidado integral no SUS. Salud \& Sociedad, v. 19, n.1, p. 70-85, 2018.

FOUCAULT, M. História da Loucura na Idade Clássica. 8 ed. São Paulo: Perspectiva, 2009.

GUARIDO, R. A medicalização do sofrimento psíquico: considerações sobre o discurso psiquiátrico e seus efeitos na Educação. Educação e Pesquisa, v. 33, n. 1, p. 151-161, 2007.

JORGE, M. S. B. et al. Promoção da Saúde Mental. Tecnologias do cuidado: vínculo, acolhimento, co-responsabilização e autonomia. Ciência e Saúde Coletiva, v. 16, n. 7, p. 3051-3060, 2011.

LOBOSQUE, A. M. Debatendo alguns desafios da Reforma Psiquiátrica brasileira. Ciência e Saúde Coletiva, v. 16, n. 12, p. 4590-4602, 2011.

MACEDO, J. P. et al. A regionalização da saúde mental e os novos desafios da Reforma Psiquiátrica brasileira. Saúde \&. Sociedade, v. 26, n. 1, p. 155-170, 2017.

MENDES, E. V. As Redes de Atenção à Saúde. 2 ed. Brasília: Organização Pan-Americana de Saúde, 2011.

MERHY, E. E. Em busca do tempo perdido: a micropolítica do trabalho vivo em saúde. In: MERHY, E. E.; ONOCKO, R. (Orgs.). Agir em saúde: um desafio para o público. 3 ed. São Paulo: Hucitec, 2007. p. 71-112.

. Saúde: a cartografia do trabalho vivo. São Paulo: Hucitec, 2005.

MINAYO, M. C. S. O desafio do conhecimento: pesquisa qualitativa em saúde. 14 ed. Sáo Paulo: Hucitec, 2014.

MORIN, E. Ciência com consciência. 15 ed. Rio de Janeiro: Bertrand Brasil, 2013.

Introdução ao pensamento complexo. 5 ed. Porto Alegre: Sulina, 2015.

ONOCKO-CAMPOS, R. T. et al. Gestão autônoma da medicação: uma intervenção analisadora de serviços em saúde mental. Ciência \& Saúde Coletiva, v. 18, n. 10, p. 28892898, 2013.

ORGANIZAÇÃO PAN-AMERICANA DA SAÚDE. Atenção à saúde coordenada pela Atenção Primária à Saúde: construindo as redes de atenção no SUS: contribuiçóes para o debate. Brasília: OPAS, 2011.

PITTA, A. M. F. Um balanço da Reforma Psiquiátrica brasileira: instituições, atores e políticas. Ciência e Saúde Coletiva, v. 16, n. 12, p. 4579-4589, 2011.

SANTOS, A. R. Contribuiçóes epistemológicas do pensamento complexo para a compreensão da pesquisa social. Textos \& debates, v. 20, p. 81-99, 2011.

THORNICROFT, G.; TANSELLA, M. Boas práticas em saúde mental comunitária. Barueri: Manole, 2010. 


\section{Nota}

${ }^{1}$ D. K. R. R. Lima contribuiu com o desenvolvimento da pesquisa, coleta e análise dos dados, elaboração do manuscrito. J. Guimarães colaborou como orientadora da tese que deu origem ao manuscrito e na revisão da versão final do artigo. 


\section{Abstract}

Articulation of the Psychosocial Care Network and local continuity of care: problematizing possible relationships

The article discusses the ways of articulation of the Psychosocial Care Network (RAPS), considering the recursiveness established between them and the characteristics of continued care in the territory. This is a field research, with a qualitative approach, conducted with 22 subjects; the scenario were RAPS Natal-RN services. Focus groups and descriptive observation were performed, and the results were submitted to thematic content analysis, grouped into two categories: 1) The aligned network: embroidering islands of resistance between the asylum reminiscences - discussing the characteristics of mental health care of community base developed in the municipality; and 2) The reconnection of wires and knots by aligning the network - discussing the strategies adopted to promote interconnections that favor the continuity of mental health care in the territory. Attention is drawn to the recursiveness established between local care and the articulation of RAPS. A care based on specialty, medicalization and fragmentation is the product and producer of a punctually articulated network, in an alignment triggered by labels and intersubjectivities.

> Keywords: mental health; mental health services; healthcare. 